\title{
Pandemia e merenda escolar: silenciamentos, dissimulações e efeitos de sentido nas normas de distribuição dos kits de alimentação nas escolas públicas
}

\author{
Pandemic and school breakfast: silences, disguises and effects of meaning in the \\ distribution rules for food kits in public schools
}

Gabriela Alves de Arruda

Doutoranda em Educação

Universidade Federal de Alagoas - UFAL

Maceió, Alagoas - Brasil

gabriela.a.arruda@hotmail.com

Dennys Dikson

Doutor em Letras e Linguística

Universidade Federal do Agreste de Pernambuco - UFAPE

Garanhuns, Pernambuco - Brasil.

dennys.dikson@ufape.edu.br

Resumo: O presente artigo traz uma investigação analítico-discursiva da Lei 13.987/2020, da Resolução 02/2020 FNDE ${ }^{1}$ e da Cartilha de orientação do $\mathrm{PNAE}^{2}$, normatizações da União destinadas ao controle, orientação e distribuição da merenda durante o período pandêmico da COVID-19, através de kits escolares. Fundamentados na Análise do Discurso fundada e desenvolvida por Michel Pêcheux (2009), e nas investigações de Orlandi (2007, a; 2007,b), Florêncio et al. (2009), dentre outros, realizamos análises dessas legislações, desvelando efeitos de sentido e construções discursivo-ideológicas carregados de silenciamentos e dissimulações das responsabilidades alimentares e educacionais inerentes ao Estado.

Palavras chave: análise do discurso; merenda escolar; kit de alimentação escolar; programa nacional de alimentação escolar; políticas públicas da educação.

Abstract: This article presents an analytical-discursive investigation of Law 13.987/2020, of Resolution 02/2020 FNDE and of the PNAE guidebook, Union regulations aimed at the control, orientation and distribution of meals during the pandemic period of COVID- 19, through school kits. Based on Discourse Analysis (PÊCHEUX, 2009), and Orlandi's investigations (2007,a; 2007,b), Florêncio et al. (2009), among others, carried out analyzes of these laws, revealing effects of meaning and discursiveideological constructions loaded with silences and disguises of the food and educational responsibilities inherent to the State.

Keywords: discourse analysis; school lunch; school feeding kit; national school feeding program; public education policies.

Cite como

\section{(ABNT NBR 6023:2018)}

ARRUDA, Gabriela Alves; DIKSON, Dennys. Pandemia e merenda escolar: silenciamentos, dissimulações e efeitos de sentido nas normas de distribuição dos kits de alimentação nas escolas públicas. Dialogia, São Paulo, n. 40, p. 1-14, e20505, jan./abr. 2022. Disponível em: https://doi.org/10.5585/40.2022.20505.

American Psychological Association (APA)

Arruda, G. A., \& Dikson, D. (2022, jan./abr.) Pandemia e merenda escolar: silenciamentos, dissimulações e efeitos de sentido nas normas de distribuição dos kits de alimentação nas escolas públicas. Dialogia, São Paulo, 40, p. 1-14, e20505. https://doi.org/10.5585/40.2022.20505.

${ }^{1}$ Fundo Nacional de Desenvolvimento da Educação.

${ }^{2}$ Programa Nacional de Alimentação Escolar. 


\section{Introdução}

O presente artigo tem como objetivo analisar discursivamente, mediante os fundamentos teórico-metodológicos da Análise do Discurso (AD) fundada por Michel Pêcheux e ancorado no Materialismo Histórico Dialético, as atuais normas que autorizaram e regulamentaram a entrega dos kits de alimentação comprados com recursos do Programa Nacional de Alimentação Escolar (PNAE), durante o período pandêmico do COVID-19 que teve início no primeiro trimestre de 2020.

Intentamos, a partir do corpus que forma a nossa materialidade discursiva (composta da Lei 13.987/20, da Resolução n. 02/2020do FNDE e da Cartilha de orientação para execução do PNAE confeccionados no período da pandemia), fazer alguns recortes epistemológicos, dando origem a sequências discursivas (SDs) que serão os lugares de análises e de desvelamentos de sentidos e posições ideológicas.

A AD, em especial a pecheutiana ${ }^{3}$, é um campo fértil que, a partir da década de 60 , iniciou um trabalho que vem permitindo atravessar as fronteiras do campo das ciências humanas, deslocar conceitos, estruturas e normas, para realizar, tendo o discurso enquanto objeto de análise, as interpretações necessárias ao conhecimento produzido pela humanidade, nas relações políticas, sociais e históricas.

Tais discursos, aflorados dessas relações humanas, possuem a característica de se constituírem de outros discursos - sempre são atravessados pelo outro, aquilo já-dito anteriormente. Por exemplo, um texto remete a pelo menos duas abordagens díspares: aquela em que se toma partido, defendendo-a, e aquela em que ele faz oposição, isso em múltiplos discursos vindos da memória anterior e se atualizando enquanto é dito. Há, sempre, vozes e ecos de outros pontos de vista, de outras formações discursivas que se intercruzam (ORLANDI, 2007a).

A $\mathrm{AD}$ tece seu embasamento partindo da noção de que a materialidade específica da ideologia é o discurso e a materialidade específica do discurso é a linguagem. Nessa perspectiva, a relação língua, discurso e ideologia fica evidenciada no sujeito (PÊCHEUX, 1975). Orlandi afirma que não há discurso sem sujeito e não há sujeito sem ideologia: "o indivíduo é interpelado em sujeito pela ideologia e é assim que a língua faz sentido" (2007a, p. 19).

Tendo essas noções enquanto pressupostos de reflexão, o presente trabalho tem como foco analisar discursivamente as normas legais que autorizaram e regulamentaram a entrega dos kits de alimentação escolar em período pandêmico, buscando desvelar/desmascarar os sentidos, por meio

\footnotetext{
${ }^{3}$ É importante ressaltar que não existe apenas uma $\mathrm{AD}$, mas diversas a depender do lugar teórico e sócio-histórico de sua fundação. Como dito, aqui nos filiamos à vertente da AD francesa, fundada e desenvolvida por Michel Pêcheux.
} 
das categorias próprias da $\mathrm{AD}$, como as condições de produção do discurso, o dito, o não dito, o silenciado e as formações discursivas.

O objetivo em tela advém da questão norteadora do nosso trabalho: quais efeitos de sentido e posições ideológicas podemos desvelar no dito, no não-dito e no silenciado das normatizações atuais (Lei 13.987/20, Resolução n ${ }^{\circ}$ 02/2020do FNDE, e Cartilha de orientação para execução do PNAE), trazidas pelo Governo Federal, que tratam da distribuição dos kits da merenda escolar nas escolas públicas, durante este período pandêmico que estamos atravessando?

O percurso metodológico se deu por meio da pesquisa bibliográfica e documental com seleção dos documentos oficiais ${ }^{4}$ que compõem nossa materialidade discursiva. Os dados foram analisados por meio do referencial teórico-metodológico da Análise do Discurso pecheutiana (adiante discutido), ancorado no Materialismo Histórico Dialético. A pretensão é que a AD nos possibilite responder a algumas questões que nos inquietam, a partir de nosso recorte epistemológico, por meio da utilização de determinadas categorias centrais de análise, como forma de apreender efeitos de sentido no discurso Estatal.

\section{Caminho Metodológico}

\subsection{Corpus, Recorte Epistemológico e Sequência Discursiva}

Neste trabalho, vamos assumir a noção de corpus desenvolvida pela AD e definida por Courtine (1981, p. 24) como

[...] um conjunto de sequências estruturadas de acordo com um plano definido referente a um certo estado das condições de produção de um discurso. A constituição de um corpus discursivo é, com efeito, uma operação que consiste em realizar, por um dispositivo material uma certa forma (isto é, estruturado de acordo com um plano), as hipóteses emitidas na definição dos objetivos de uma pesquisa (apud CAVALCANTE, 2007, p. 14).

No processo de organização das sequências discursivas do corpus fomos guiados pelo nosso objetivo de pesquisa, buscando realizar recortes pertinentes a analisar qual o real interesse e o que está silenciado no discurso das normas que nortearam a aquisição e entrega dos kits alimentação alusivos à merenda escolar, em período pandêmico do COVID-19. Ainda na definição do corpus, o analista pode optar, no caminho da análise

${ }^{4}$ Os documentos oficiais foram a Lei n.13.987, de 7 de abril de 2020, a Resolução n ${ }^{\circ}$ 02, de 09 de abril de 2020 e a Cartilha de Orientações para Execução do PNAE, disponíveis nos sites:

http://www.planalto.gov.br/ccivil_03/_ato2019-2022/2020/lei/113987.htm

http://www.fnde.gov.br/index.php/acesso-a-informacao/institucional/legislacao/item/13453-resolu\%C3\%A7\%C3\%A3o-n\%C2\%B0-02,-de09-de-abril-de-2020

https://www.fnde.gov.br/index.php/programas/pnae/pnae-area-gestores/pnae-manuais-cartilhas, todos acessados em 13/12/2020. 
[...] por organizar as sequências discursivas de várias maneiras, a saber: por uma sequência discursiva ou por várias; produzidas por um locutor ou por vários; produzidas a partir de posições ideológicas homogêneas ou heterogêneas, dentre outras possibilidades (COURTINE, 2009, p. 57).

Dessa forma, a partir do corpus que forma a nossa materialidade discursiva - composta da lei 13.987/20, da Resolução n. 02/2020do FNDE e da Cartilha de orientação para execução do PNAE no período pandêmico -, iremos fazer alguns recortes epistemológicos, dando origem a sequências discursivas (SDs) para análise e desvelamentos de sentidos.

O recorte epistemológico é o momento metodológico em que retiramos/recortamos/separamos do corpus um determinado segmento (sendo normas legais, recortamos um artigo ou um parágrafo ou um inciso ou alínea, por exemplo); desse segmento, chega-se ao momento de sublimarmos as sequências discursivas (SDs) que utilizaremos para desvelar os sentidos, através das análises discursivas.

Para tornar mais didática esta diferenciação, podemos utilizar a metáfora do funil: na parte maior e larga estaria o corpus ou materialidade discursiva (no nosso caso seria o conjunto formado pela lei 13.987/20, pela Resolução n. 02/2020do FNDE e pela Cartilha de orientação para execução do PNAE no período pandêmico), no meio do funil, em um segundo momento, estaria o recorte epistemológico, e no final, onde fica o "bico", o local mais estreito, estariam as sequências discursivas. Aprofundando esta analogia, após a nossa materialidade discursiva passar por este funil, permeado pelo filtro das categorias da $\mathrm{AD}$, teríamos como resultado o desvelamento dos sentidos, o desmascaramento do que está silenciado no discurso destas normas, além do lugar ideológico a partir do qual o sujeito fala, maquiado no texto legal.

\subsection{A materialidade discursiva para análise}

A Lei n ${ }^{\circ}$ 13.987, de 7 de abril de 2020, que autorizou, em caráter excepcional, a distribuição de gêneros alimentícios adquiridos com recursos do PNAE aos pais ou responsáveis dos estudantes das escolas públicas de educação básica, alterou a Lei no 11.947, de 16 de junho de 2009 (Lei do PNAE). De acordo com essa alteração legislativa, a distribuição dos alimentos da merenda escolar poderá ser feita todas as vezes em que as aulas da rede pública forem suspensas, em razão de situação de emergência ou de calamidade pública, sempre em caráter excepcional.

A legislação é originária do Projeto de Lei 786/2020, do deputado Hildo Rocha (MDBMA). O texto afirma que o dinheiro do PNAE continuará a ser repassado pela União a estados, municípios e Distrito Federal para a compra de merenda escolar, mesmo com aulas suspensas. Como as escolas públicas estão fechadas por conta da pandemia, os alimentos deverão ser 
distribuídos imediatamente aos pais ou aos responsáveis pelos estudantes matriculados, por meio de kits de alimentação.

Acerca dos alunos, segundo o Censo Escolar 2019, o Brasil tem quase 39 milhões de crianças e adolescentes matriculados na rede pública de educação básica, as quais fazem pelo menos uma refeição (em boa parte dos casos, a única) na escola, por meio da merenda escolar. Daí a robusta relevância dessa nova Lei, para garantir a alimentação escolar desses alunos, em especial dos mais pobres, com os recursos do PNAE, porém entregue diretamente aos pais dos alunos ou responsáveis por eles (familiares, tutores ou curadores), a fim de garantir o Direito Humano à Alimentação Adequada durante a pandemia.

Dessa forma, pais e responsáveis pelos alunos matriculados na educação infantil (creche e pré-escola, de zero a cinco anos), ensino fundamental (de seis a 14 anos) e ensino médio (de 15 a 17 anos) poderão receber os gêneros alimentícios, através de kits, adquiridos pelas escolas públicas com os recursos do PNAE.

Após sansão da referida Lei, o Fundo Nacional de Desenvolvimento da Educação (FNDE) confeccionou, em 13 de abril de 2020, a Resolução $n^{\circ}$ 2/2020 que regulamenta a aquisição e distribuição da merenda durante o período de emergência. A Resolução é composta por 10 artigos, subdivididos em parágrafos, que trazem direcionamento, orientação e normatização exatamente sobre a execução do PNAE durante o período de estado de calamidade pública. Cabe, a partir disso, aos Estados e Municípios definirem as melhores formas e logística de distribuição dos alimentos.

Em contínuo à Resolução, O FNDE, através do Ministério da Educação em parceria com o Ministério da Agricultura, Pecuária e Abastecimento, com o fito de auxiliar todos esses gestores do executivo, publicou uma Cartilha intitulada Orientações para a execução do PNAE durante a situação de emergência decorrente da pandemia do corona vírus (COVID-19). Nela, há orientações de planejamento, recebimento e distribuição dos alimentos; composição dos kits; direcionamentos nutricionais da merenda; controle de saúde e higiene na manipulação; como distribuir; a importância da aquisição a partir da agricultura familiar, dentre outras orientações, para que o PNAE pudesse funcionar a contento durante a pandemia. Essa cartilha de orientação é composta de 26 páginas, dividindo-se em títulos e subtítulos que tratam sobre o planejamento, o recebimento e a distribuição de alimentos.

Assim, esses três documentos oficiais - a Lei, a Resolução e a Cartilha - serão a materialidade, o corpus de nossa pesquisa. O Recorte Epistemológico efetuado para este momento investigativo, foi a Resolução $n^{\circ} 02 / 2020$, especificamente o art. $2^{\circ} \operatorname{com}$ seu $\int 1^{\circ}$, os quais estão 
devidamente transcritos mais adiante no momento das análises. Dentro desse Recorte, realizamos, enfim, o afunilamento analítico a três sequências discursivas (SDs) que serão, de fato, os lugares do aprofundamento das categorias da AD para desvelamento de sentidos.

É muito importante ressaltar a relevância de deixar clara essa distinção entre corpus, Recorte Epistemológico e SDs em trabalhos discursivos, tendo em vista que ainda vemos muitos estudantes, professores e até pesquisadores na área da $\mathrm{AD}$ confundirem tais conceitos ou apresentarem definições divergentes quanto a cada um desses termos, o que pode ocasionar problemas metodológicos e analíticos, especialmente no tratamento dos dados. Por isso, devemos entender que o traçado se inicia com o detalhamento do corpus, para após se fazer o Recorte Epistemológico, para, então, definirem-se as sequências discursivas a serem analisadas.

\section{Fundamentos e Análises}

\subsection{As Condições de Produção}

Ao optar pelo discurso como objeto de estudo, Pêcheux (1995) considera que são as determinações sociais, políticas e econômicas que incidem sobre o discurso assentado nas relações sociais nas quais o sujeito está incluído. Assim, o que interessa não é o que uma palavra ou expressão significa, mas como funciona o discurso a partir de uma conjuntura sócio-histórica determinada (PÊCHEUX, 1995).

Para a AD, é por meio dos discursos que as formações ideológicas se expressam, a partir das posições políticas, constituindo dessa forma as bases para as formações discursivas, sustentando o dizer. As formações ideológicas por meio dos jogos de sentidos podem dissimular os sentidos. Para entendermos como esses discursos se constituem, como produzem sentidos e como os mesmos atuam na realidade, é necessário buscar as condições sócio-históricas-ideológicas em que são produzidos.

Sobre as Condições de Produção, Florêncio et. al (2016, p. 36) afirmam:

[...] para que possamos entender como essa categoria - Condições de Produção - é fundamental na análise de um discurso, precisamos concebê-lo em seus dois sentidos: amplo e estrito. O primeiro, expressa as relações de produção, com sua carga sóciohistórica-ideológica. $\mathrm{O}$ segundo, diz respeito às condições imediatas que engendram a sua formulação. (2016, p. 36 - grifo nosso)

No que diz respeito às Condições de Produção Amplas, cabe salientar a importância deste programa de alimentação escolar que é o cerne de nosso trabalho - o PNAE-, já que estamos dialogando sobre o Direito Humano à Alimentação Adequada (DHAA), e segurança alimentar e 
nutricional e soberania alimentar (popular). O reconhecimento normativo internacional da existência de um DHAA aparece já na própria Declaração Universal dos Direitos Humanos, em seu art. 25, e no Pacto Internacional de Direitos Econômicos, Sociais e Culturais - PIDESC (BRASIL, 1992), em seu art. 11.

$\mathrm{Na}$ exegese do Comitê de Direitos Humanos Econômicos, Sociais e Culturais da ONU, no que diz respeito à alimentação adequada, expressa no Comentário Geral no 12 ao PIDESC, o referido direito inclui o acesso "estável e permanente a alimentos saudáveis, seguros e sadios, em quantidade suficiente, culturalmente aceitos, produzidos de uma forma sustentável e sem prejuízo da implementação de outros direitos para as presentes e futuras gerações” (ONU, 1999, grifamos).

O embrião do PNAE aqui no Brasil surge em 1950 com o objetivo de amenizar a fome e a desnutrição que atingia consideravelmente uma parcela da população brasileira. Após longas modificações durante o decorrer dos anos, em busca da qualificação da merenda escolar, o Brasil sanciona, em 2009, a lei que viria a regulamentar este Programa.

No caso em tela, os beneficiários da merenda escolar são alunos da educação infantil (creches e pré-escolas), do ensino fundamental, da educação de jovens e adultos, da educação indígena, das áreas remanescentes de quilombolas e alunos da educação especial matriculados em escolas públicas dos estados e municípios ${ }^{5}$ (ou seja, classes desfavorecidas economicamente na sociedade).

Ainda sobre essas Condições Amplas, é importante entendermos ser o tema alimentação (na escola) de grande relevância científica e social, tendo em vista que houve a recepcionalidade do Brasil quanto aos direitos reconhecidos nos tratados internacionais de direitos humanos, por meio do art. $5^{\circ}, \int 2^{\circ}$, da Constituição Federal $(\mathrm{CF})$, como direitos fundamentais, o que torna o direito humano à alimentação adequada um direito constitucional de todo cidadão brasileiro. Não fosse isso suficiente, a leitura dos arts. $3^{\circ} ; 5^{\circ}$, caput $5^{\circ}$, XXIII; $6^{\circ} ; 7^{\circ}$, IV; 23, VIII e X; 170; 184; 186; 193; 196; 200, VI; 203; 208, VII; 226, \ 8º e 227 da CF (1988), evidencia a presença do direito humano à alimentação adequada [e escolar] no cerne dos problemas sociais e das políticas públicas da atualidade, o que deixa mais ainda o tema em relevo, com uma contextualização social e história dentro dos parâmetros constitucionais.

O Programa, segundo o Ministério da Educação, atende cerca de 41 milhões de alunos e configura um dos principais acessos à alimentação em âmbito nacional. Conforme dados do Instituto Brasileiro de Geografia e Estatística (IBGE), das mais de 54 milhões de pessoas que vivem

\footnotetext{
${ }^{5}$ Fonte: portal do FNDE - Fundo Nacional de Desenvolvimento da Educação. (http://www.fnde.gov.br/programas/alimentacao-escolar) acesso em $17 / 01 / 2021$.
} 
na extrema pobreza no Brasil hoje, 14 milhões têm menos de 14 anos. Ou seja, para muitos desses estudantes, a única refeição do dia é realizada, justamente, na escola.

Isso nos faz entender a relevância que a segurança nutricional e alimentar desponta dentro do direito humanístico. Cenário este em que as políticas públicas ganham grande força, já que é por meio delas que é possível uma maior acessibilidade das pessoas marginalizadas ao usufruto dos Direitos Humanos; e o PNAE, através da merenda escolar, é, sem sombra de dúvidas, uma das maiores e mais importantes políticas públicas educacionais do país, pois atinge crianças e jovens estudantes de todos os recantos do Brasil, os quais necessitam de uma merenda digna e de qualidade.

No que diz respeito às Condições de Produção Restritas, no Brasil, uma vez reconhecido o estado de calamidade pública por meio de decreto legislativo, em decorrência da crise da COVID-19, o país passou a adotar medidas de distanciamento e isolamento social (pelo menos em tese). Com isso, visando ao urgente emprego de medidas de prevenção, as atividades letivas das escolas públicas e particulares tiveram de ser suspensas e, consequentemente, no caso do ensino público, milhares de estudantes brasileiros ficaram sem acesso à merenda escolar.

Nesse sentido, exatamente por conta dessa suspensão preventiva das aulas, em 7 de abril de 2020 foi sancionada a lei 13.987/20, já anteriormente comentada, seguida da Resolução e da Cartilha para orientação da entrega dos kits escolares. Esse detalhamento das Condições Amplas e Restritas, relativo justamente às condições imediatas que engendram a sua formulação (FLORENCIO et al, 2016), auxilia-nos exatamente a compreender como a história e o atual se intercruzam; demonstrando, outrossim, nossa materialidade discursiva em relevo dentro desse processo social do que fora realizado quanto à merenda escolar desde sua criação até o momento atual desta distribuição na conjuntura de pandemia.

\section{Resolução $\mathrm{n}^{\circ}$ 02/2020: do silêncio ao dissimulado}

Vamos, agora, às análises. Primeiro vejamos nosso Recorte Epistemológico, o artigo $2^{\circ} \mathrm{e}$ seu $\int 1^{\circ}$ da Resolução 02/2020:

Art. $2^{\mathbf{o}}$ Os estados, municípios, o Distrito Federal e as escolas federais deverão utilizar os recursos do PNAE exclusivamente para garantir a alimentação dos estudantes da educação básica.

$\int 1^{\circ} \mathrm{Na}$ hipótese prevista no caput, os gêneros alimentícios já adquiridos ou que vierem a ser adquiridos em processos licitatórios ou em chamadas públicas da agricultura familiar poderão ser distribuídos em forma de kits, definidos pela equipe de nutrição local, observando o per capita adequado à faixa etária, de acordo com o período em que o estudante estaria sendo atendido na unidade escolar. (os grifos foram nossos) 
A partir desse Recorte, selecionamos três Sequências Discursivas para analisarmos e discutirmos seus efeitos de sentido, desmudando o dito, o não-dito e o silenciado que delas afloram.

\subsection{Sequência Discursiva 1 (SD1)}

SD1: “os gêneros alimentícios já adquiridos ou que vierem a ser adquiridos em processos licitatórios ou em chamadas públicas da agricultura familiar”

Nessa primeira SD, vamos observar que o dito está encobrindo um não-dito: os gêneros alimentícios de uma boa parte das escolas públicas do país já foram, antes da pandemia, devidamente fornecidos. E sabemos que esse fornecimento, pelo menos sua maioria, é realizado por grandes empresas de alimentos industrializados; geralmente com baixo teor nutritivo, por meio de compras efetivadas por licitações (diversas vezes manipuladas, fraudulentas e superfaturadas, conforme vemos nos noticiários diários) com as edilidades municipais, mantendo a classe dominante com a detenção dos lucros, já que não existe uma preocupação com o desenvolvimento sustentável, muito menos com a agricultura familiar.

Em todo discurso, se faz presente o silêncio. O silêncio, como afirma Orlandi (2007a), é anterior à fala. No silêncio, está a palavra; quando pronunciada, rompe-o. Não é mais silêncio, é sentido. Florencio et. al. ensinam que

\footnotetext{
há, pois, um silêncio necessário que é a presença, condição para que se realize o processo de constituição do sentido, do sujeito e da incompletude própria da linguagem. Ao falar, o sujeito tem necessariamente uma relação com o silêncio, pois não se pode dizer tudo; se assim o fizesse, estaria incorrendo, no excesso do dizer, na ausência de sentido. Desse modo, o silencio é fundamento para que o sujeito produza sentido e o restaure em cada dizer (2016, p. 81).
}

No movimento do silêncio, Orlandi classificou suas formas em:

a) o silêncio fundador, aquele que existe nas palavras, que significa o não-dito e que dá espaço de recuo significante, produzindo as condições para significar; e b) a política do silêncio, que se subdivide em: b 1) silêncio constitutivo, o que nos indica que para dizer é preciso não-dizer (uma palavra apaga necessariamente as "outras" palavras); e b 2) o silêncio local, que se refere à censura propriamente (àquilo que é proibido dizer em uma certa conjuntura) (2007b, p. 24, grifos da autora).

O que está fortemente silenciado nesta SD1 é que os alimentos, inclusive os agrícolas, na verdade são fornecidos pelos grandes latifundiários, fazendeiros e produtores rurais de larga escala, restando uma pouca margem de fornecimento pelo agricultor familiar. Embora a SD1 diga explicitamente "agricultura familiar", a intenção do sujeito (o Governo Federal através do MEC) 
desse discurso é exatamente silenciar a realidade dos fatos, da origem e da compra dessas merendas, configurando-se uma dissimulação ilusória e irreal àqueles que de fato necessitam, os alunos de escolas públicas.

O que percebemos é que esses ditos são colocados no jogo discursivo com muita ênfase de convencimento para que os não-ditos (cf. ORLANDI, 2007) possam ficar na penumbra, como se disfarçados estivessem. É necessário, para o Estado, que a realidade não se desvele, pois isso viria a revelar uma política educacional estatal precária que, infelizmente, temos como herança do descaso sociocultural e histórico que perdura há muitas décadas.

O discurso é, então, utilizado, enquanto silêncio fundador, para esconder o que realmente ocorre: o apoio às grandes indústrias, aos grandes empreendedores, ao capitalismo, à ideologia dominante; com alimentos superfaturados, cheios de corrupção política, apresentando preços elevados para manter o lucro excessivo, e por vezes de baixa qualidade. Ou seja, não há uma preocupação com os alunos que são os destinatários da merenda, por isso o Estado carreia o termo "chamadas públicas da agricultura familiar" para silenciar que o que de fato acontece: a mercantilização da merenda com o intuito da manutenção da classe rica no poder e perpetuação da ideologia neoliberal.

\subsection{Sequência discursiva 2 (SD2)}

SD2: "poderão ser distribuídos em forma de kits, definidos pela equipe de nutrição local"

Impressiona o que a SD2 diz. Será que há, de fato, equipe de nutrição local? Nem parece ser uma legislação brasileira, confeccionada num país de terceiro mundo, com um histórico continuum de corrupção, de escolas sem equipes técnicas como nutricionistas [psicólogos, assistentes sociais], e de desvios de verbas públicas destinadas às políticas públicas inclusivas como os que ocorrem com a merenda escolar.

A realidade é que a falta de nutricionistas e de diversos outros profissionais (SILVA et al., 2018) ${ }^{6}$ é um dos principais obstáculos para que as escolas ofereçam merenda de qualidade nutritiva adequada aos estudantes, em especial aos que possuem restrições alimentares ou que se situam em cidades e bairros de periferia e paupérrimos. Não existe, embora a SD2 seja enfática em dizer “equipe de nutrição local". No máximo o que vemos na nossa prática diária de convivência social, é um profissional de nutrição contratado pela edilidade municipal (principalmente em cidades

\footnotetext{
${ }^{6}$ A pesquisa de Silva et al. (2018), com base no PNAE, em estudo transversal analítico com 214 municípios, demostrou a falta recorrente de nutricionistas nas escolas e creches públicas ou, quando há, a presença desses profissionais ocorre, normalmente, com frequência apenas semestral, situação que vem acarretando gravíssimos problemas nutricionais aos alunos.
} 
pequenas) para dar conta de todo município, comparecendo às escolas apenas esporadicamente ou trabalhando apenas nas secretarias de ação social.

O dito, de fato, forja um não-dito, já que inexiste (na grande maioria das escolas) equipe de nutrição local. Não há nada de averiguação nutricional. A lei é dissimulada e fantasiosa. O Estado - utilizando o MEC enquanto pano de fundo -, assume uma posição política extremamente duvidosa por subverter a verdade dos fatos e o estado real de nossa merenda educacional e os problemas que lhe dizem respeito.

É necessário, também, para a manutenção do mascaramento dessa realidade ideológicodiscursiva impregnada na Legislação, que a SD2 da Resolução n. 02/2020 não diga que a alimentação, quando existe diariamente nas escolas públicas, nem sempre é saudável e nem sempre é adequada. Ao mesmo tempo, causa a falsa impressão de que essa diretriz está sendo seguida, silenciando sobre o fato de que em relação ao dito "kits, definidos pela equipe de nutrição local", não condiz com a realidade - os alimentos fornecidos são industrializados e padronizados, não se respeitando a cultura local alimentar dos beneficiários e muito menos os hábitos alimentares saudáveis.

\subsection{Sequência Discursiva 3 (SD3)} FNDE:

Nosso último recorte para análise será do $\int 2^{\circ}$, do art. $2^{\circ}$, da Resolução $n^{\circ} 02 / 2020$ do

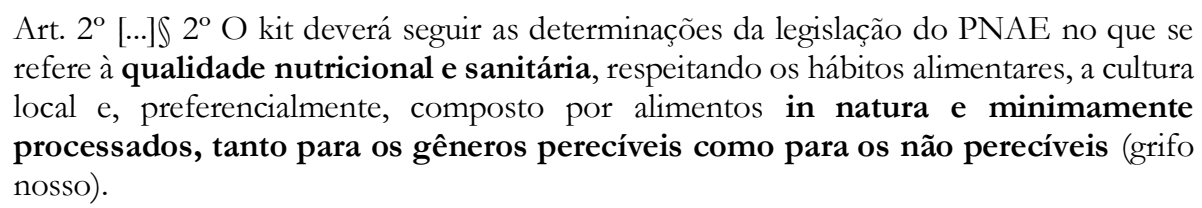

Afunilando o lugar analítico, extraímos a Sequência Discursiva 3:

SD3: “qualidade nutricional e sanitária, respeitando os hábitos alimentares, a cultura local e, preferencialmente, composto por alimentos in natura e minimamente processados"

Forja-se, neste dito, uma manutenção da "qualidade" da educação e da preocupação do Governo Federal com os alunos de escolas públicas pela e através da alimentação, com um discurso de convencimento que diz ser o sistema educacional excelente e em perfeito funcionamento. A formação discursiva vai-se constituindo a partir da ideologia dominante tão cara ao MEC.

Busca-se, assim, convencer a sociedade (e em especial a população/alunos constituinte da educação pública) de que essa "qualidade nutricional e sanitária” é proporcionada pelo PNAE.

${ }^{7}$ O Governo Federal não disponibiliza informações acerca de quais alimentos deveriam ser a base de composição dos kits de meren da escolar. 
Sendo assim, observa-se a presença de um deslocamento de sentido do termo "qualidade da educação" condicionada à oferta de alimentação. Há, nesse caso, um jogo com o equívoco, já que a escola é uma instituição que tem como finalidade o ensino e a aprendizagem.

O que há, na verdade é um pequeno incentivo, para a aquisição de gêneros alimentícios in natura, produzidos pela agricultura familiar, ou seja, não existe uma priorização como o parágrafo diz. Esse discurso é utilizado para silenciar o que de fato acontece - da mesma maneira que na SD2: o apoio às grandes indústrias, aos grandes empreendedores, ao capitalismo, à ideologia dominante, com alimentos superfaturados, com preços elevados para manter o lucro excessivo, com alimentos de baixa qualidade.

A destinação real do capital público (formado por nossos impostos) vai às empresas de grande porte que, por sua vez, fornecem uma alimentação de qualidade nutricional duvidosa, padronizada, fortemente processada, por vezes em quantidade menor do que a necessária e extremamente superfaturada, perdurando e perpetuando o poder da classe dominante. Procura-se, neste $\ 2^{\circ}$, produzir discursos paralelos, com efeitos de sentido manipuladores, sempre com o intuito de encobrir a finalidade e a destinação dos recursos da merenda escolar.

\section{Considerações finais}

Intentamos identificar os discursos manipuladores e impositores de uma ideologia neoliberal aos que dependem diretamente da alimentação na educação pública constituída neste momento pandêmico pelos "kits escolares", entendendo como esses sujeitos, interpelados pela ideologia mercadológica, são afetados pelos efeitos de sentido de discursos da classe dominante que paira na Resolução no 02/2020 do FNDE.

Concluímos, através das análises feitas, que os discursos construídos na Resolução $\mathrm{n}^{\circ}$ 02/2020 em nada contribuem para melhorar a realidade vigente; ao contrário, contribuem para a manutenção da ordem do capital, no que diz respeito a recursos financeiros da merenda pública, mais uma vez deflagrando os vieses que caminham na conjuntura educacional brasileira, que são formulados por lugares exclusivamente voltados ao mercadológico e à classe que possui o poder, concretizado por uma ideologia que é representada por formações discursivas das formas mais explícitas, implícitas e silenciadas possíveis.

Outrossim, a Resolução, na verdade, é uma falácia, tendo em vista ser fato notório que os gêneros alimentícios não têm nada de diversificados e nada de minimamente processados, como a Lei impõe, já que eles são fornecidos pelas grandes empresas de alimentos industrializados, com baixo teor nutritivo, por meio de compras efetivadas por licitações com as edilidades municipais, 
mantendo a elite em seu lugar, no poder, sem demonstrar preocupação prática com o desenvolvimento sustentável, nem com a agricultura familiar. Quando os alimentos são agrícolas, são fornecidos pelos grandes latifundiários, fazendeiros e grandes produtores rurais, restando uma pouca - ou nenhuma - margem de fornecimento pelo agricultor familiar.

Os discursos analisados são utilizados para silenciar nossa triste e recorrente realmente: o apoio às grandes indústrias, aos grandes empreendedores, ao capitalismo, ao domínio; alimentos superfaturados, preços elevados para manter o lucro excessivo, baixa qualidade. Ou seja, não há uma preocupação efetiva com os alunos que são os destinatários da merenda e a quem são direcionados os kits escolares. Embora o discurso da Resolução silencie, é fato a mercantilização da merenda, que, em momento pandêmico, aproveita-se da situação para gerir mais lucro, mantendo a classe dominante no topo da pirâmide da ideologia neoliberal.

Enquanto ainda não avançamos na garantia plena de direitos sociais, é preciso dar vez e vOz (e assim procuramos fazer através das análises dos discursos) às ações de solidariedade que dialoguem com a agricultura familiar, apontando alternativas aos brasileiros para enfrentar a COVID-19, tão subestimada pelo atual governo Bolsonaro, e garantir o sustento daqueles que trabalham diariamente pela saúde e segurança alimentar da população. Afinal, quando falamos sobre o PNAE, é preciso compreender que estamos dialogando sobre o Direito Humano à Alimentação Adequada, Segurança Alimentar e Nutricional e Soberania Alimentar (Popular).

\section{Referências}

ARRUDA, Gabriela Alves de. Do direito à merenda escolar ao discurso do direito: uma análise discursiva do programa nacional de alimentação escolar - PNAE.

Dissertação de Mestrado. Programa de Pós-Graduação em Educação. Universidade Federal de Alagoas. Maceió, 105p., 2018.

BEUERLEN, Alexandra. (et al). Direito à Alimentação Adequada/Grupo de Trabalho "Alimentação Adequada". Brasília: Escola Superior do Ministério Público da União, Manuais de Atuação ESMPU, 2008, v.6.

BRASIL, Constituição Federal de (1988) - VadeMecum. São Paulo: Rideel, 2009.

BRASIL. Presidência da República. Decreto 591: Atos Internacionais. Pacto Internacional sobre Direitos Econômicos, Sociais e Culturais. Brasília, 1992.

BRASIL. Ministério da Educação. Lei no 11.947, de 16 de junho de 2009. Disponível em: http://www.planalto.gov.br/ccivil_03/_ato2007-2010/2009/lei/111947.htm Acesso em: 23/01/2017.

BRASIL. Ministério da Educação. Resolução/CD/FNDE no 38, de 16 de julho de 2009. Disponível em: http://www.fnde.gov.br/fnde/legislacao/resolucoes/item/3341resolu $\% \mathrm{C} 3 \% \mathrm{~A} 7 \% \mathrm{C} 3 \% \mathrm{~A} 3 \mathrm{o}-\mathrm{cd}-$ fnde-n $\% \mathrm{C} 2 \% \mathrm{BA}-38$-de-16-de-julho-de-2009 acesso em: $23 / 01 / 2017$. 
BRASIL, Presidência da República. Cartilha Nacional da Alimentação Escolar. Ministério da Educação - FNDE/MEC, Brasília-DF, 2014.

BRASIL, Presidência da República. Constituição da República Federativa do Brasil de 1988. Disponível em: http://www.planalto.gov.br/ccivil_03/constituicao/constituicaocompilado.htm acesso em: 23/01/2017.

CAVALCANTE, Maria do Socorro Aguiar de Oliveira. Qualidade e cidadania nas reformas da educação brasileira: o simulacro de um discurso modernizador. Maceió: Edufal, 2007.

CAVALCANTE (org.). As malhas de discursos (re)veladores. Maceió: EDUFAL, 2005.

COURTINE, Jean-Jacques. [1981]. Análise do Discurso: o discurso comunista endereçado aos cristãos. Tradução de Bacharéis em Letras pela Universidade Federal do Rio Grande do Sul. São Carlos: EdUFSCar, 2009 apud CAVALCANTE, Maria do Socorro Aguiar de Oliveira. Qualidade e cidadania nas reformas da educação brasileira: o simulacro de um discurso modernizador. Maceió: Edufal, 2007.

COURTINE. Análise do discurso politico: o discurso comunista endereçado aos cristãos. São Paulo: EDUFSCAR, 2009.

DIKSON, Dennys; ARRUDA, Gabriela Alves de. "Ideologia e efeitos de sentido: Um olhar discursivo na Cartilha Nacional de Alimentação Escolar". SIGNOTICA (UFG), v. 29, p. 553-574, 2017.

FLORÊNCIO, Ana Maria Gomes [et al.]. Análise do discurso: fundamentos \& práticas. Maceió: Edufal, 2016.

MAGALHÃES, Belmira. As marcas do corpo contando bistória: um estudo sobre a violência doméstica. Maceió: EDUFAL, 2005.

ORLANDI, Eni. Análise de discurso: princípios \& procedimentos. $7^{\mathrm{a}}$ Edição. Campinas: Pontes, 2007a.

ORLANDI. As formas do silêncio: no movimento dos sentidos. Campinas: UNICAMP, 2007b.

ORLANDI. Discurso, imaginário social e conhecimento. In: Em Aberto, Brasília, ano 14, n. 61, jan/mar. 1994.

ORLANDI. "A análise do discurso em suas diferentes tradições intelectuais: o Brasil". In: Anais do $1^{\circ}$ Seminário de Estudos em Análise do Discurso. 2003, Nov 10-13. Porto Alegre (RS): UFRGS, 2003.

PÊCHEUX, Michel.; FUCHS, Catherine. "A propósito de análise automática do discurso: atualização e perspectivas” (1975) In: GADET, Françoise, HAK, Tony. Por uma análise automática do discurso: uma introdução à obra de Michel Pêcheux, 4a. ed. Campinas/ SãoPaulo:Editora UNICAMP, 2010.

PÊCHEUX, Michel. Semântica e discurso: uma crítica à afirmação do óbvio. Campinas: Unicamp, 1995.

SARAIVA, Elisa Braga et al. "Panorama da compra de alimentos da agricultura familiar para o Programa Nacional de Alimentação Escolar”. Ciência \& Saúde Coletiva, v. 18, n. 4, p. 927-936, 2013.

ZIEGLER, Jean. Relatório do relator especial do direito à alimentação. Submetido de acordo com a Resolução n. 2000/10 da Comissão de Direitos Humanos. Nações Unidas, Conselho Econômico e Social.

E/CN.4/2001/53, quinquagésima sétima sessão, 7 fev. 2001. 